\title{
Fine Structure of Spore Germination in Botrytis cinerea
}

\author{
By K. GULL AND A. P. J. TRINCI \\ Microbiology Department, Queen Elizabeth College \\ (University of London), Campden Hill, London W.8
}

(Accepted for publication I9 July 1971)

\begin{abstract}
SUMMARY
The ultrastructure of germinating Botrytis cinerea conidia was studied using three different fixatives. Good fixation and embedment of dormant spores was achieved. The wall of the dormant spore was composed of two layers. During germination three new wall layers were formed between the original wall and the cytoplasm; the inner two layers were continuous around the spore cytoplasm whilst the third was formed only near the point of germ-tube emergence and was continuous with the germ-tube wall. The conidial wall increased in thickness from 263 to $339 \mathrm{~nm}$. during germination. It was calculated that, as a result of spore swelling alone, the dormant spore wall would decrease in thickness from 263 to $178 \mathrm{~nm}$. An apical corpuscle was observed in the germ-tube wall during germination.
\end{abstract}

\section{INTRODUCTION}

Most ultrastructural studies of fungal spore germination have been made using $\mathrm{KMnO}_{4}$ as the sole or main fixative. Attempts at fixing fungal spores with glutaraldehyde or osmium tetroxide have frequently met with little or no success (Buckley, Sjaholm \& Sommer, 1966; Bartnicki-Garcia, Nelson \& Cota-Robles, I968a). Further, it is generally considered that even with $\mathrm{KMnO}_{4}$ fixation it is difficult to prepare satisfactory sections of dormant spores for transmission electron microscopy (Hawker, Thomas \& Beckett, 1970).

Bartnicki-Garcia (1968) recently divided fungal spores into three groups, two of which contain terrestial species, viz. type I, spores in which the germ-tube wall is continuous with part or all of the dormant spore wall, e.g. Penicillium frequentans (Hawker, 1966), Aspergillus oryzae (Tanaka, 1966) and Botrytis cinerea (Hawker \& Hendy, I963); and type III, spores in which the germ-tube wall is formed de novo within the dormant spore during germination, e.g. Gibberella persicaria (Bracker, 1966), Rhizopus nigricans and Rhizopus sexualis (Hawker \& Abbott, 1963). The type III nature of Aspergillus nidulans conidia was demonstrated in Kellenberger but not in $\mathrm{KMnO}_{4}$ fixed material by Border \& Trinci (1970). Aspergillus oryzae (Tanaka, I966) has, however, been assigned by Bartnicki-Garcia to the type I group. Because of this apparent variation within the aspergilli, Border \& Trinci (I970) advocated that spores classified as being in Bartnicki-Garcia's type I group should be re-examined by means of Kellenberger's fixation method. In the present investigation the germination of Botrytis cinerea conidia was studied using Kellenberger's, glutaraldehyde and $\mathrm{KMnO}_{4}$ fixations.

Indirect evidence of whether or not a new wall layer is formed during germination may be obtained by comparing the relative thicknesses of dormant and germinated spore walls. In the absence of apposition of new wall material during germination one would expect that the original wall of the dormant spore would become stretched during swelling and hence 
thinner. Thus in an evaluation of the processes of wall development it is necessary to estimate wall volume.

\section{Organism and cultural conditions}

\section{METHODS}

Botrytis cinerea, Queen Elizabeth College strain F3, was used. Conidia harvested from I- to 2-week cultures grown on Oxoid malt agar were washed twice with distilled water and used to inoculate $500 \mathrm{ml}$. conical flasks containing $50 \mathrm{ml}$. DPM medium (Trinci \& Gull, 1970). The flasks were incubated at $25^{\circ}$ on an orbital shaker at $200 \mathrm{rev} / \mathrm{min}$. Conidial samples were removed at intervals after inoculation. The diameters of about 50 to 100 spores were measured in 15 min. by means of methods described by Barnes \& Parker (I966). No significant difference was observed between the mean diameters of unfixed and fixed conidia at the same stage in germination. A small proportion of the dormant spores measured was ovoid and for these the mean of the long and short axes was taken as the diameter.

Electron microscopy. Conidia were fixed at room temperature $\left(18^{\circ}\right.$ to $\left.22^{\circ}\right)$ in the following ways: (I) I \%(w/v) aqueous potassium permanganate for I h.; (2) $4 \%$ (w/v) glutaraldehyde in $0.05 \mathrm{M}$-cacodylate buffer at $\mathrm{pH} \mathbf{7 . 2}$ for $\mathrm{Io}$ h. followed by six washes in distilled water and postfixation in $I \%(w / v)$ cacodylate-buffered osmium tetroxide for $2 \mathrm{~h}$.; or (3) I \% (w/v) osmium tetroxide in Kellenberger's buffer at $\mathrm{pH} 6 \cdot 0$ for $8 \mathrm{~h}$. (Kellenberger, Ryter \& Sechaud, I958).

The conidia were dehydrated in a graded ethanol series and embedded in Spurr's embedding medium (Spurr, 1969). Sections were cut with an LKB ultramicrotome with glass knives. Sections of glutaraldehyde and osmium tetroxide fixed material were stained with $2 \%(w / v)$ aqueous uranyl acetate followed by an alkaline solution of lead citrate (Reynolds, 1963). Specimens were examined in an AEI EM6B microscope.

Light microscopy. Light micrographs of FAA fixed material (Righelato, Trinci, Pirt \& Peat, 1968) were taken with a Zeiss photomicroscope.

Measurements of spore-wall thicknesses and cytological features were made directly from the photographic plates using a $\times$ ro calibrated magnifier. The percentage of the cytoplasmic area of spores occupied by mitochondria was calculated from weights of electronmicrographs, before and after cutting out the mitochondrial areas.

Effect of spore swelling on the thickness of the dormant spore wall. During spore swelling there is an increase in the surface area of the spore. Let

$$
\begin{aligned}
y & =\text { the surface area of the dormant spore, } \\
x & =\text { the surface area of the swollen spore, } \\
\text { and } t_{\mathrm{d}} & =\text { the thickness of the dormant spore wall. }
\end{aligned}
$$

Then the surface area $(S)$ of the swollen spore expressed as a percentage of the dormant spore surface area may be calculated from the following equation

$$
S=(x / y) \times 100 .
$$

If the volume of the dormant wall material remains constant it can only cover the increased spore surface area by becoming thinner. The thickness of the wall after swelling $\left(t_{\mathrm{s}}\right)$ may be calculated from the following equation

$$
t_{\mathrm{s}}=t_{\mathrm{d}} \times(\mathrm{I} 00 / S)
$$

The values of the surface areas used in the above equation were arrived at by assuming the spores to be spherical. A small proportion of the dormant spores was not spherical; this, however, should not have a significant effect upon the calculations. 
RESULTS

Swelling of conidia and production of germ tubes. The increase in diameter of Botrytis cinerea conidia was linear during the first $10 \mathrm{~h}$. after inoculation (Fig. I); the mean diameter increased from 10.3 to $12.5 \mu \mathrm{m}$. during this period, a $21 \%$ increase. This represents increases of $79 \%$ in spore volume and $48 \%$ in spore surface area. At Io h. most conidia had produced one germ tube (Fig. 2). Subsequently some conidia produced a second and third germ tube (Fig. 2).

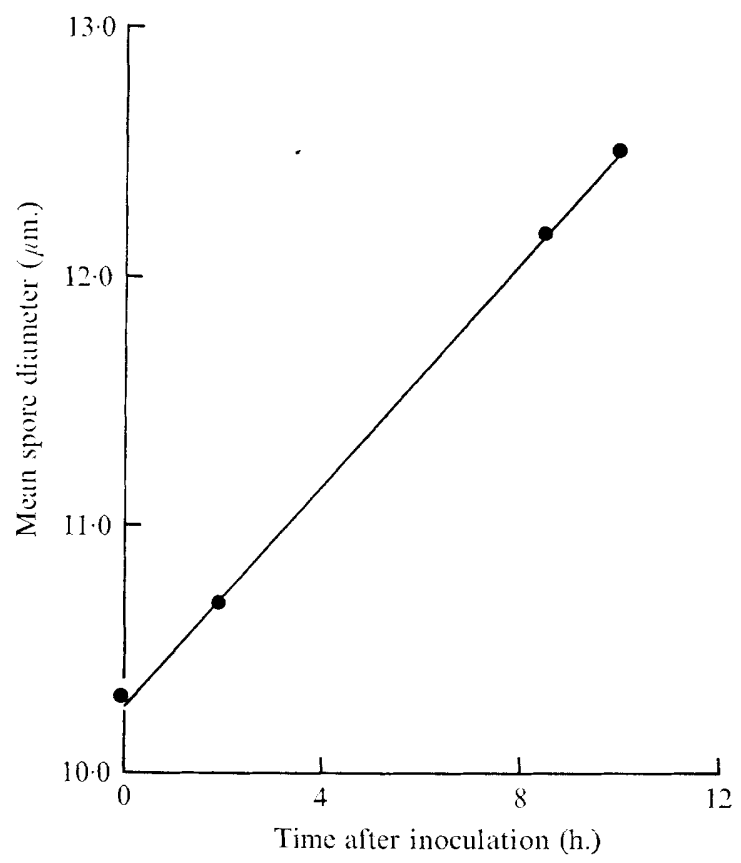

Fig. I. Increase in mean diameter of Botrytis cinerea conidia with time.

Ultrastructure of the dormant conidium. $\mathrm{KMnO}_{4}$ and Kellenberger's osmium tetroxide, but not glutaraldehyde, fixed dormant spores well (Fig. $3 a, b$ ), revealing a typical eukaryotic cellular organization. In the dormant conidium, mitochondria were usually round to ovoid in section. The sparse endoplasmic reticulum was made up of short profiles scattered throughout the cytoplasm (Fig. $3 a$ ). Three to six nuclei were commonly observed per spore section, a similar number to that reported by Buckley et al. (1966). Nucleoli were visible in Kellenberger fixed conidia (Fig. $3 b$ ). Dormant and germinating conidia frequently contained storage bodies similar to those reported by Buckley et al. (I966). These were most often seen around the periphery of the cytoplasm (Fig. 5a) and especially at the poles of the conidium (Fig. $3 c$ ). The wall of the dormant spore was composed of an outer thin electrondense layer $\left(D_{1}\right)$ and an inner electron-translucent layer $\left(D_{2}\right)($ Fig. 3a,b). The structure of the wall of the dormant conidium is shown in Fig. $9 a$.

Ultrastructure of the swollen conidium. After $4 \mathrm{~h}$. incubation, two new wall layers $\left(\mathrm{N}_{1}\right.$ and $\mathrm{N}_{2}$ ) were observed in both Kellenberger's and glutaraldehyde-fixed spores (Fig. $4 b, c$ ). These wall layers were, however, not clearly differentiated in $\mathrm{KMnO}_{4}$-fixed spores (Fig. $3 c$ ). The endoplasmic reticulum content of the spore had increased at this stage and was often closely associated with nuclei (Fig. $3 c$ ). 
Ultrastructure during germ-tube emergence. Two germinated conidia are shown in Fig. $5 a$. In the germinating conidium some regions of the endoplasmic reticulum occurred as sheets of flattened cisternae usually associated with nuclei (Fig. 7a). Mitochondria increased in numbers during germination. The cross-sectional area occupied by mitochondria was calculated as a percentage of the total cytoplasmic area, excluding walls and vacuoles; mitochondria occupied $10.9 \%$ of the cytoplasmic area of dormant spores and II $6 \%$ of germinated spores. Thus, although there was an increase in mitochondrial numbers during germination, the ratio of the areas occupied by mitochondria and cytoplasm remained constant.

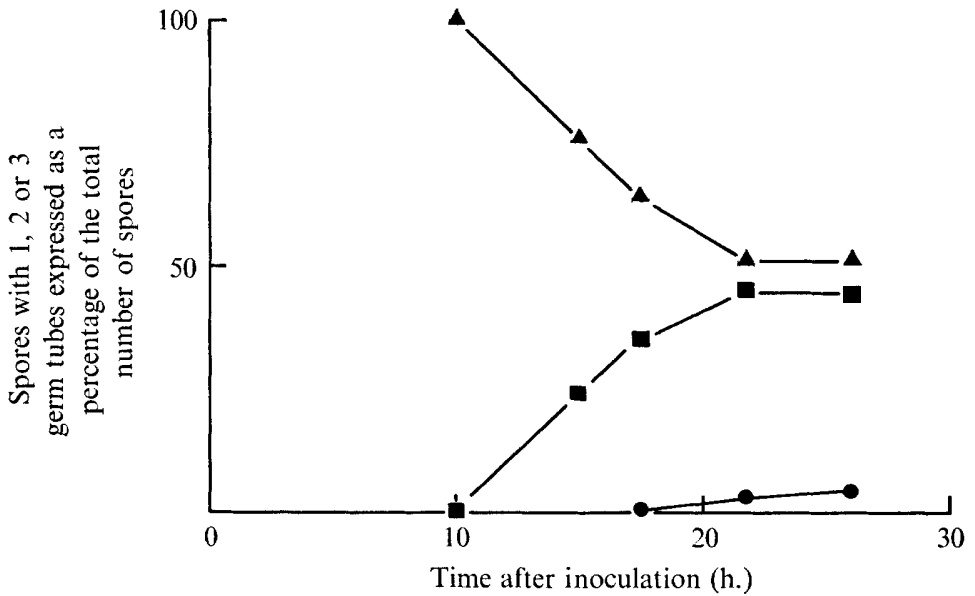

Fig. 2. Germination and production of germ tubes in Botrytis cinerea conidia. $\mathbf{\Delta}-\mathbf{\Delta}$, Percentage of spores with one germ tube; $\square-\mathbf{n}$, percentage of spores with two germ tubes; percentage of spores with three germ tubes.

As the germ tube extended, the conidium showed increasing vacuolation (Fig. $5 b$ ). The vacuoles were delimited by a single membrane and in all fixatives contained inclusions of electron-dense material. Storage bodies were preserved best in either Kellenberger's or glutaraldehyde-fixed material. The various structures apparently concerned with breakdown of storage product have been described by Buckley et al. (1966). Multivesicular bodies were observed in germinating conidia and germ tubes, but never in dormant conidia (Fig. $7 c, e$ ).

Fig. $7 d$ shows a mitochondrion surrounded entirely by a continuous double membrane. This arrangement is structurally very similar to the primary autophagic vacuoles described by De Duve \& Wattiaux (1966). These structures were seen in all three fixations but never in great abundance.

Fig. $6 a$ shows an early stage in germ-tube emergence prior to septum formation. The germ-tube wall is formed by a third new wall layer $\left(\mathrm{N}_{3}\right)$, which, unlike the $\mathrm{N}_{1}$ and $\mathrm{N}_{2}$ layers, is not continuous around the spore (Fig. $4 a$ ). It is present only at and near the point of germtube emergence. Hawker et al. (I970) have reported a similar cap of wall material over the emerging germ tube of Cunninghamella elegans.

The germ tube of Botrytis cinerea contained an apical corpuscle (Bartnicki-Garcia, Nelson \& Cota-Robles, 1968b) which usually appeared as a hemispherical structure in the germtube wall (Fig. $8 c-f$ ). Sometimes it was completely surrounded by wall material but occasionally there was a connexion between the electron dense area of the apical corpuscle and the cytoplasm. This connexion has also been observed for the apical corpuscle of Mucor 
Abbreviations used: AC, apical corpuscle; AS, abscission scar; ER, endoplasmic reticulum; L, lipid body; M, mitochondrion; MS, membranous systems; Mu, mucilage; MVB, multivesicular body; $\mathrm{N}$, nucleus; $\mathrm{Nu}$, nucleolus; $\mathrm{R}$, ribosome; $\mathrm{S}$, septum; $\mathrm{SB}$, storage body; $\mathrm{SI}$, septal initials; $V$, vesicle; VA, vacuole; W, Woronin body; $N_{1}, N_{2}, N_{3}, D_{1}$ and $D_{2}$ refer to the particular spore wall layer.
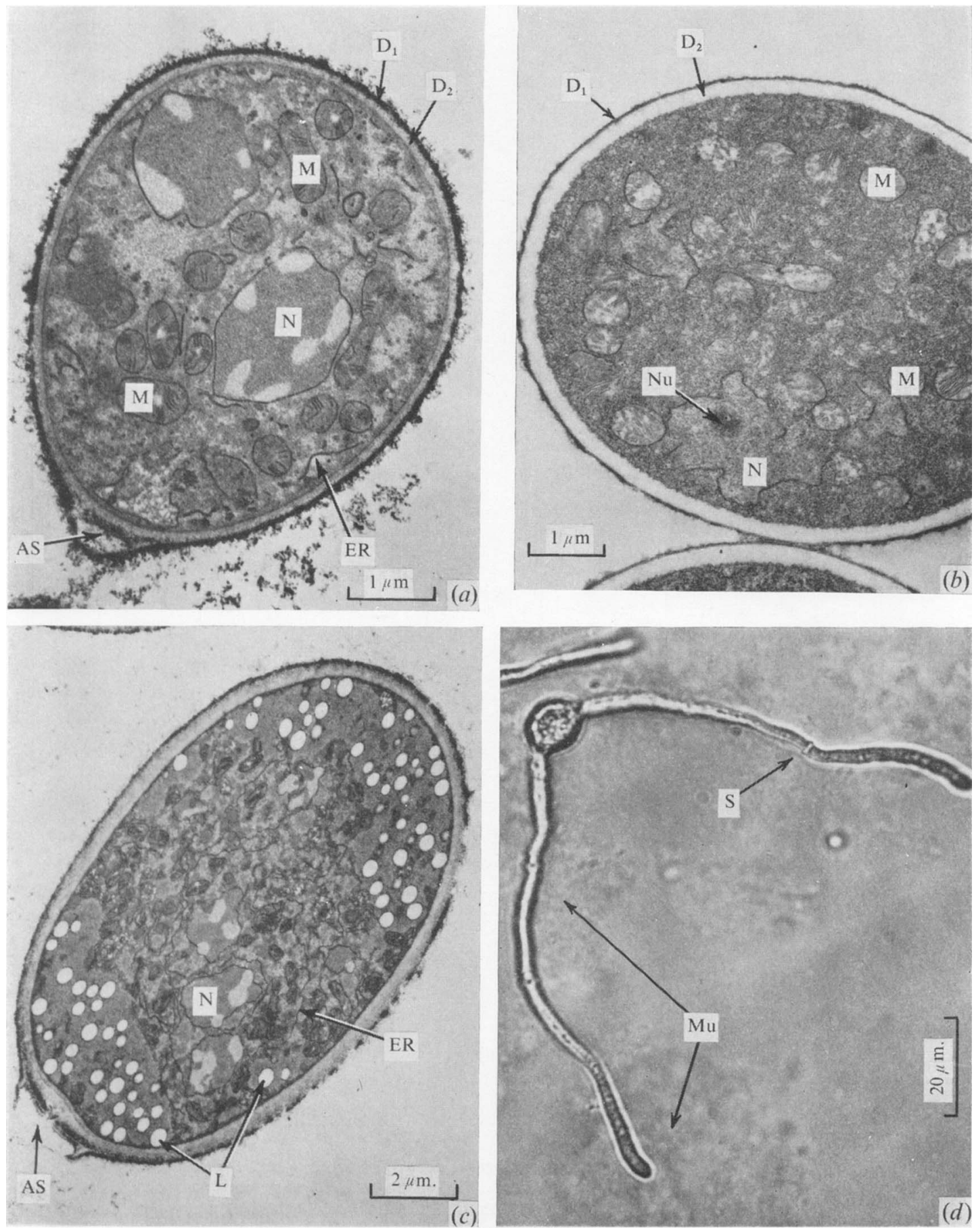

Fig. 3. (a) Dormant conidium showing two-layered spore wall. $\mathrm{KMnO}_{4}$. (b) Dormant conidium showing two-layered spore wall, large mitochondria and nuclei. Kellenberger. (c) Conidium after $4 \mathrm{~h}$. incubation in nutrient medium. The $\mathrm{N}_{1}$ layer can be seen near the abscission scar. $\mathbf{K M n O}_{4}$. (d) Light micrograph of a germinating conidium showing two germ tubes surrounded by mucilage. 

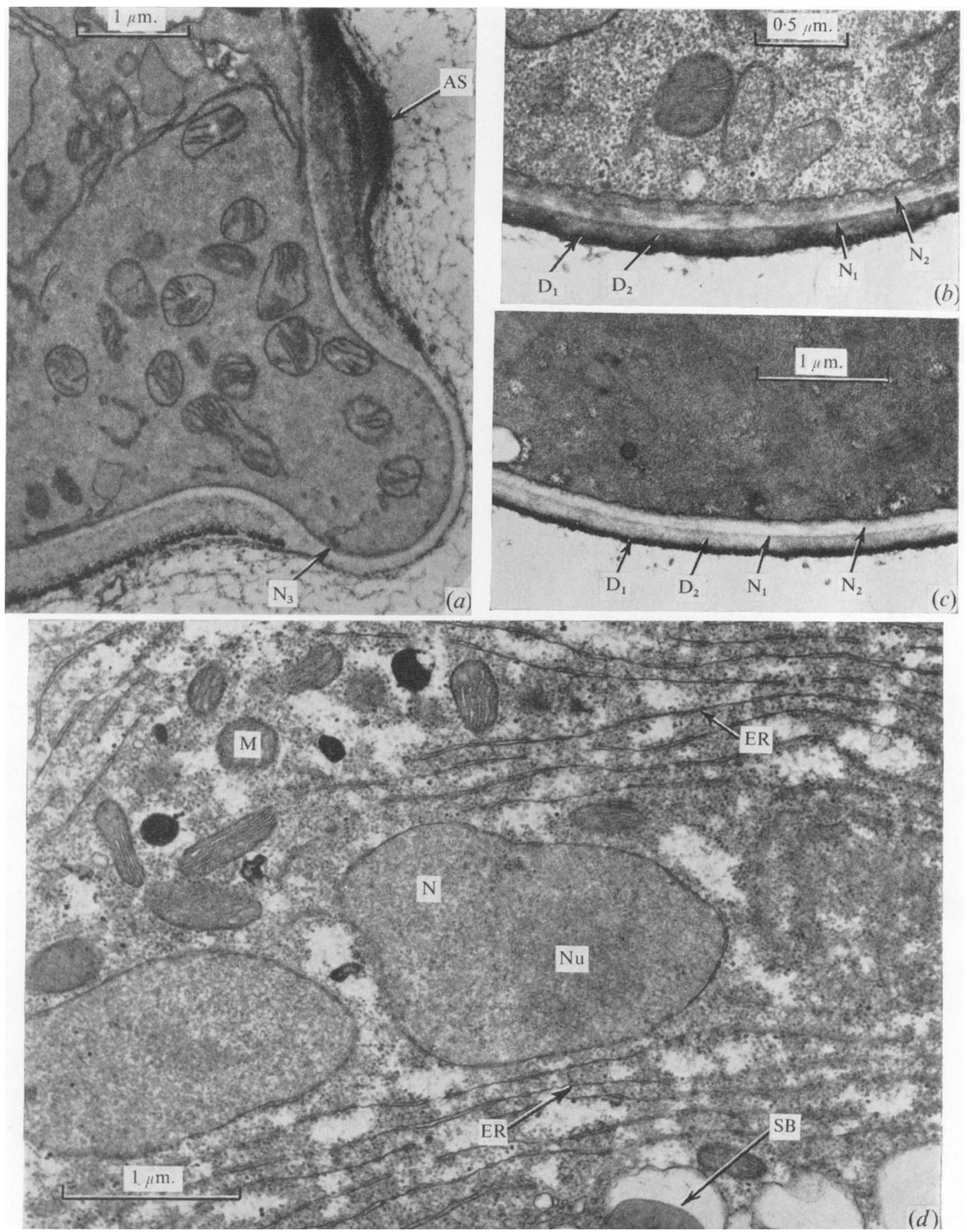

Fig. 4. (a) Near median section of an incipient germ tube after to $\mathrm{h}$. in nutrient medium showing the new wall layer $\mathrm{N}_{3} . \mathrm{KMnO}_{4}$. (b) \& (c) Wall of spore after $4 \mathrm{~h}$. incubation in nutrient medium showing the two new wall layers $\mathrm{N}_{1}$ and $\mathrm{N}_{2}$. Glutaraldehyde. (d) Cytoplasmic organization of a germ tube. Glutaraldehyde. 

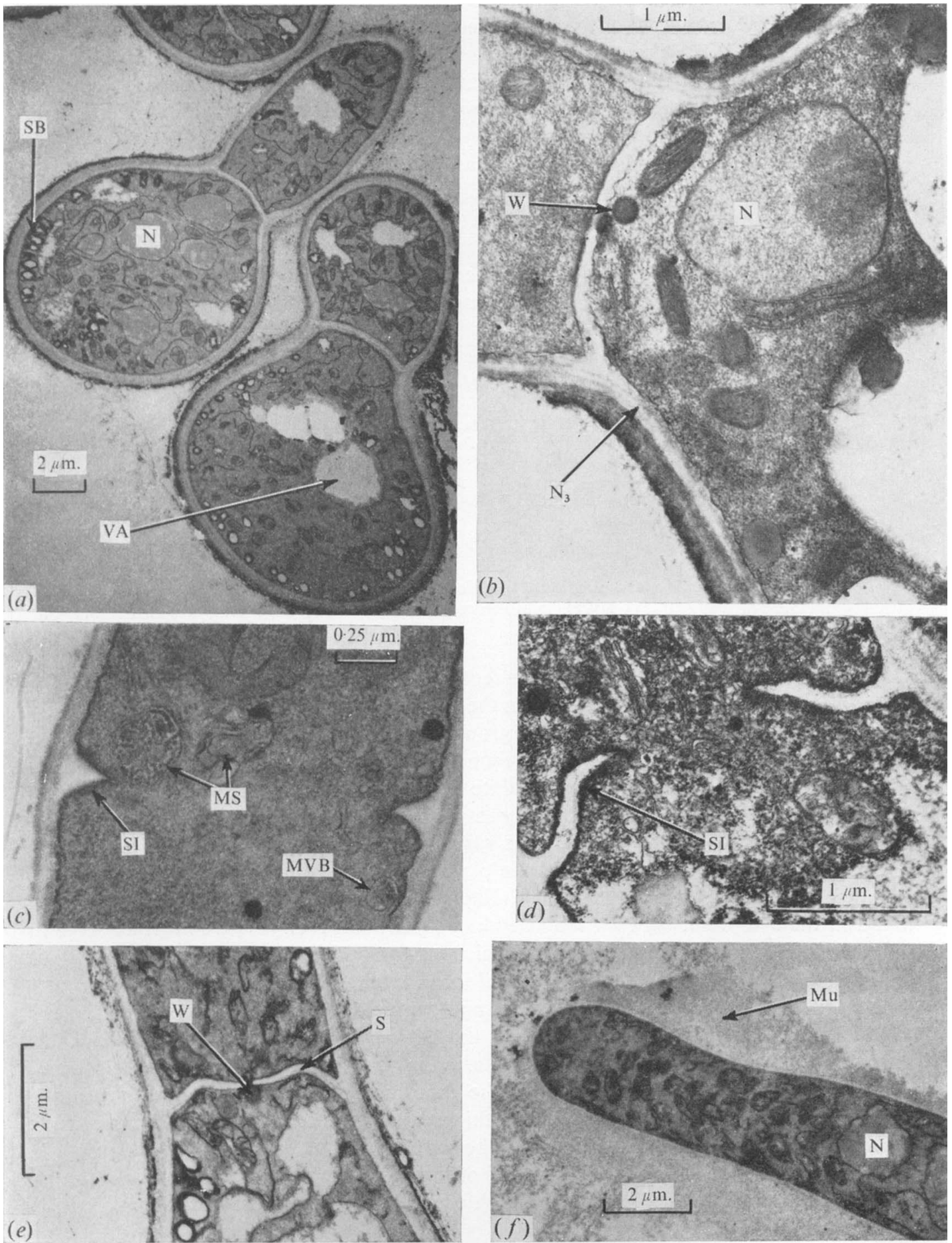

Fig. 5. (a) Two fully germinated spores showing septum at the base of the germ tube and vacuolation of the spore and germ tube. $\mathrm{KMnO}_{4}$. (b) Region of germ-tube emergence showing $\mathbf{N}_{3}$ and septum. Glutaraldehyde. (c) Developing septum of germ tube showing the triangular septal initials and the membranous systems between them. Glutaraldehyde. (d) Developing septum of germ tube showing the growth of the septal initials. Kellenberger. (e) Fully developed septum showing the central pore, plugged in this case by a Woronin body. $\mathrm{KMnO}_{4}$. $\quad(f)$ Near median section of a germ tube showing the mucilaginous covering. $\mathrm{KMnO}_{4}$. 
rouxii (Bartnicki-Garcia et al. 1968 ). Possibly this form of apical corpuscle is a stage in its development. The cytoplasm of the newly emerged germ tube contained a large number of vesicles (Fig. $8 c-f$ ). The electron-dense core of the apical corpuscle sometimes had a membranous appearance. Fig. $8 b$ shows a germinated spore with the apical corpuscle situated on the side of the germ-tube wall. The outer wall layers have become detached in this spore. This occurred only rarely in $B$. cinerea.

Soon after its formation the germ tube was covered by a mucilaginous sheath (Fig. $3 d$; Fig. $5 f$ ). Both transverse and longitudinal sections through the germ tube showed structure characteristic of ascomycetous hyphae (Fig. $5 f$; Fig. $8 a$ ). Long profiles of endoplasmic reticulum surrounded the nucleus (Fig. $4 d$ ), whilst the storage bodies in various stages of breakdown were situated towards the periphery of the hypha. The nuclear membrane was sometimes seen to be continuous with the endoplasmic reticulum (Fig. $7 b$ ).

\section{Table I. Observed width of wall layers of dormant and swollen conidia (nm.) of Botrytis cinerea}

$D_{1}$ and $D_{2}$ represent wall layers present in the dormant spore;
$\mathrm{N}_{1}$ and $\mathrm{N}_{2}$ represent wall layers formed during spore germination.
$\begin{array}{cccc}\text { Time of } \\ \text { incubation (h.) } & \mathrm{D}_{1} \text { and } \mathrm{D}_{2}{ }^{*} & \mathrm{~N}_{1} \text { and } \mathrm{N}_{2}{ }^{*} & \begin{array}{c}\text { Total conidial } \\ \text { wall thickness }\end{array} \\ \text { o } & 263 & - & 263 \\ \text { I0 } & \text { I } 80+ & 159 & 339\end{array}$

* Each measurement is the mean of at least 25 different conidia.

$\uparrow$ The thickness of the $D_{1}$ and $D_{2}$ layers in swollen conidia, estimated on the assumption of stretching but no addition of material, was $178 \mathrm{~nm}$.

Soon after formation of the germ tube a septum with a single central pore developed at the point of emergence of the germ tube from the spore (Fig. $5 e$ ). Woronin bodies were closely associated with the septal pore. Because growth of fungal septa is usually very rapid (e.g. 3 to 7 min. in Ascodesmis sphaerospora (Brenner \& Carroll, 1968) and Io min. in Rhizoitonia solani (Bracker \& Butler, 1963) it is difficult to obtain information on ultrastructural aspects of septum growth. Fig. $5 c$ shows an early stage in septum formation; electron-translucent material has been deposited on the inner surface of the germ-tube wall. This material is always triangular in cross-section and the plasmalemma is continuous over it, sometimes forming a bleb at the apex of the triangle (Fig. $5 c$ ). Multivesicular bodies were consistently found in the cytoplasm between the extending septal rim (Fig. $5 c, d$ ). A further stage in septum formation is shown in Fig. $5 d$ in which a cross-wall has been formed by growth of the triangular 'septal initials'. A fully developed septum is shown in Fig. $5 e$.

The thickness of wall layers of dormant and germinated spores fixed in Kellenberger's medium was measured (Table I). Although the spore had swelled, the total wall thickness at $\mathrm{Io}$ h. was greater than that at $\mathrm{oh}$. The observed increase in the thickness of the spore wall at Io h. (Table I) was presumably due to the apposition of new wall material to form the new wall layers $\mathrm{N}_{1}$ and $\mathrm{N}_{2}$. The theoretical thickness of the stretched dormant wall at $\mathrm{Io} \mathrm{h}$. was calculated using the method outlined above and found to be $178 \mathrm{~nm}$. This figure is in close agreement with the observed thickness of the $\mathrm{D}_{1}$ and $\mathrm{D}_{2}$ layers in swollen spores after Io h. incubation (Table $\mathrm{I}$ ). The events which occur during germination are summarized in Fig. 9. 

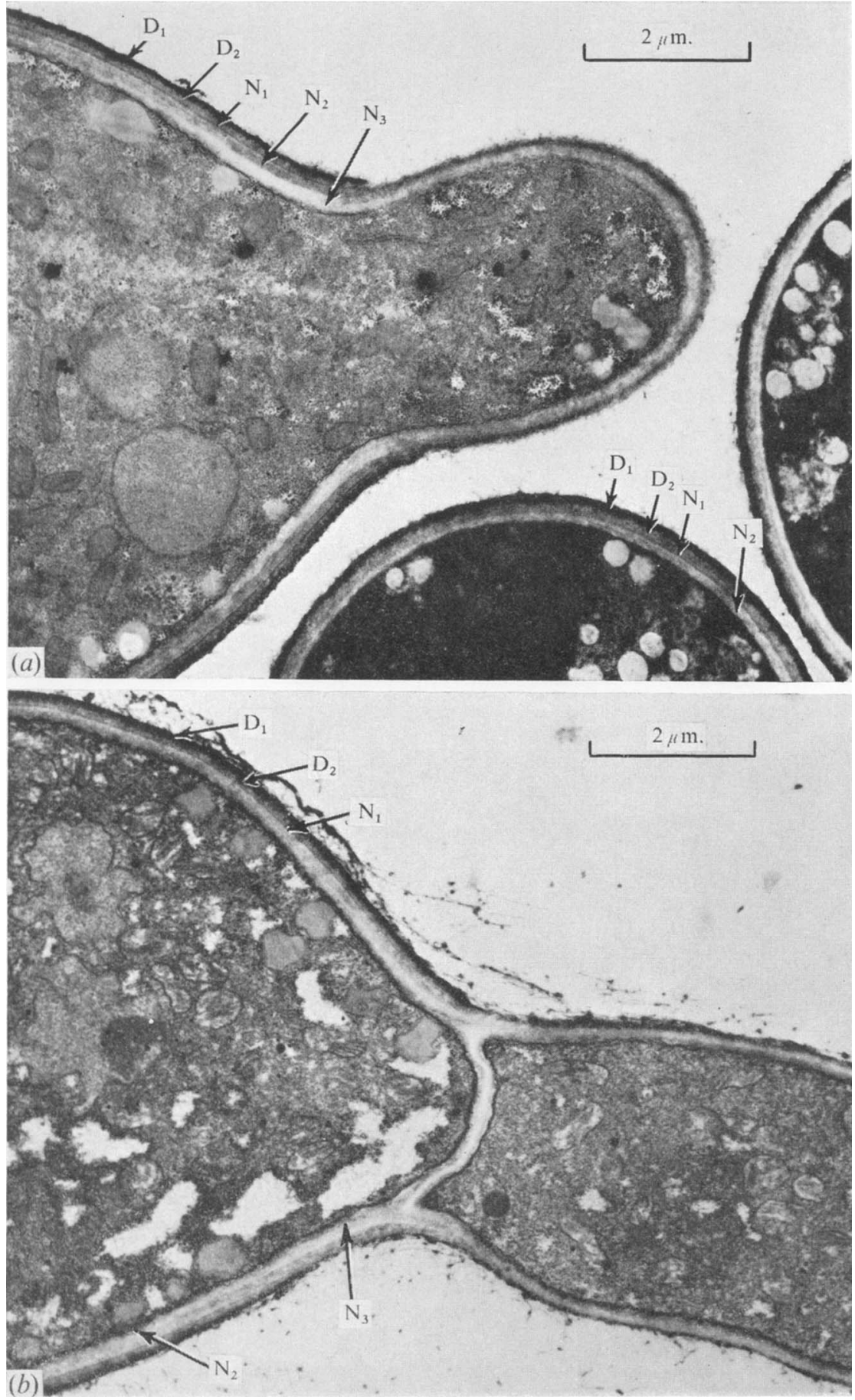

Fig. 6. (a) Newly emerged germ tube showing new wall layers $\mathrm{N}_{1}, \mathrm{~N}_{2}$ and $\mathrm{N}_{3}$. The other spores show the new wall layers $\mathbf{N}_{1}$ and $\mathbf{N}_{2}$. Glutaraldehyde. (b) Glancing section of spore showing new wall layers $N_{1}$ and $N_{2}$ and the septum. The septum develops with the $\mathrm{N}_{3}$ layer as a foundation. Kellenberger. 

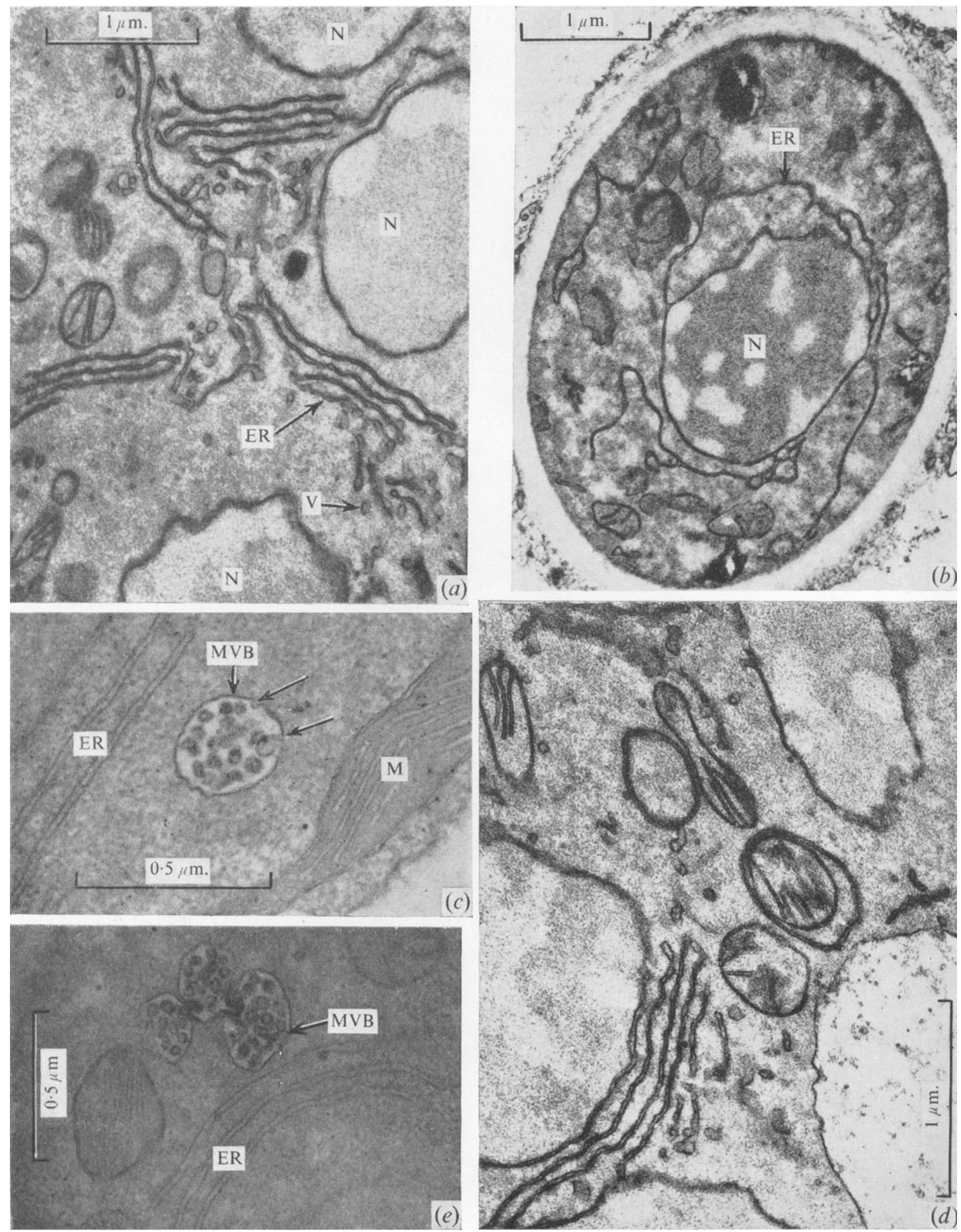

Fig. 7. (a) Cytoplasm of a germinating spore. Note the endoplasmic reticulum near the nuclei. $\mathrm{KMnO}_{4}$. (b) Transverse section of a germ tube. Note the connections between the endoplasmic reticulum and the nuclear membrane. $\mathrm{KMnO}_{4}$. (c) Multivesicular body in germ tube. Note the invaginations in the bounding membrane (arrowed). Glutaraldehyde. (d) Mitochondrion surrounded by double membranes. $\mathrm{KMnO}_{4}$. (e) Multivesicular bodies in germ tube. Glutaraldehyde. 

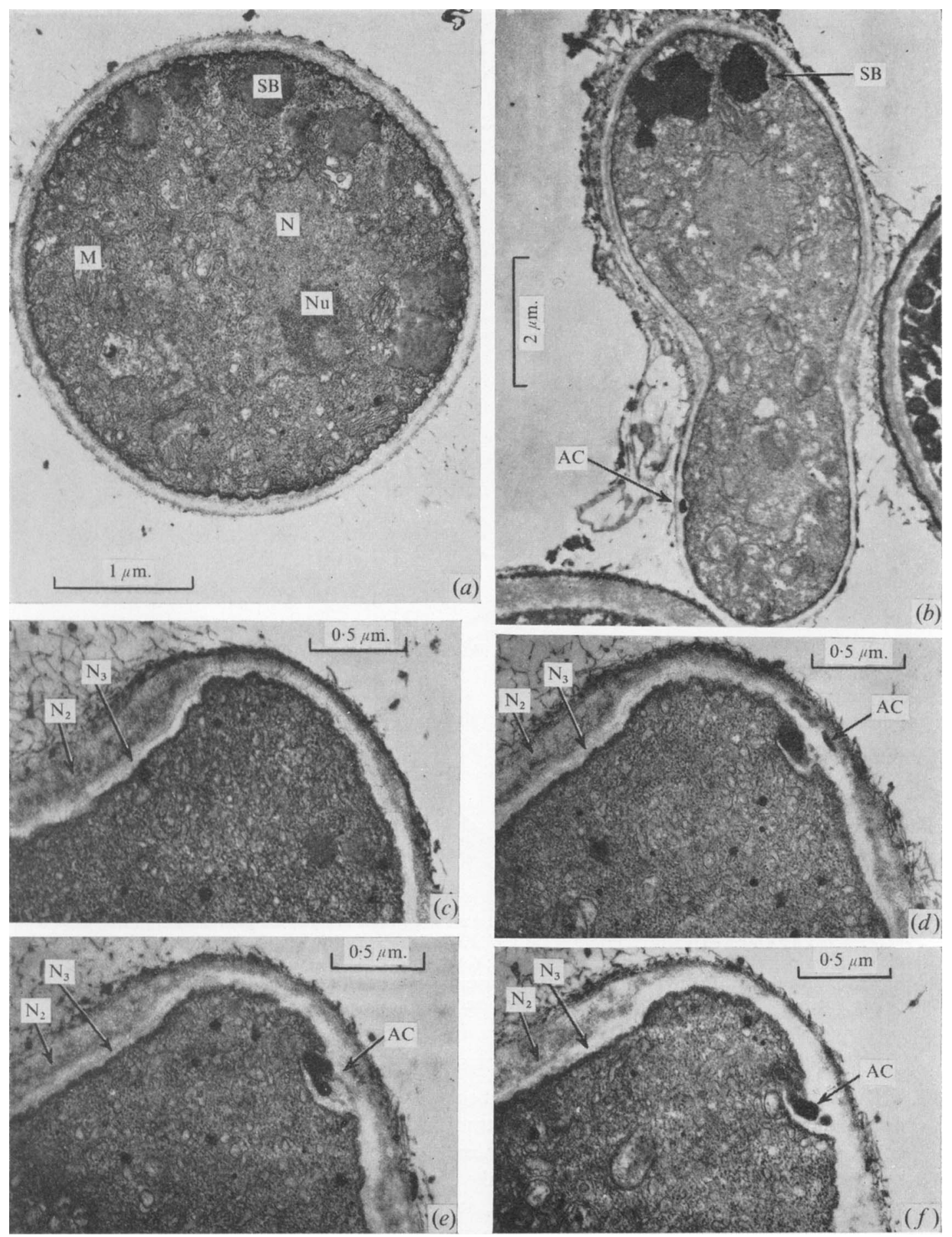

Fig. 8. (a) Transverse section of a germ tube. Note nucleolus and numerous cytoplasmic vesicles. Kellenberger. (b) Section of a germinating spore showing the apical corpuscle in the side wall of the germ tube. Kellenberger. $(c-f)$ Serial sections through the tip of an incipient germ tube. Note the apical corpuscle in three of the sections, showing it to be a discrete organelle. Kellenberger. 
(a)
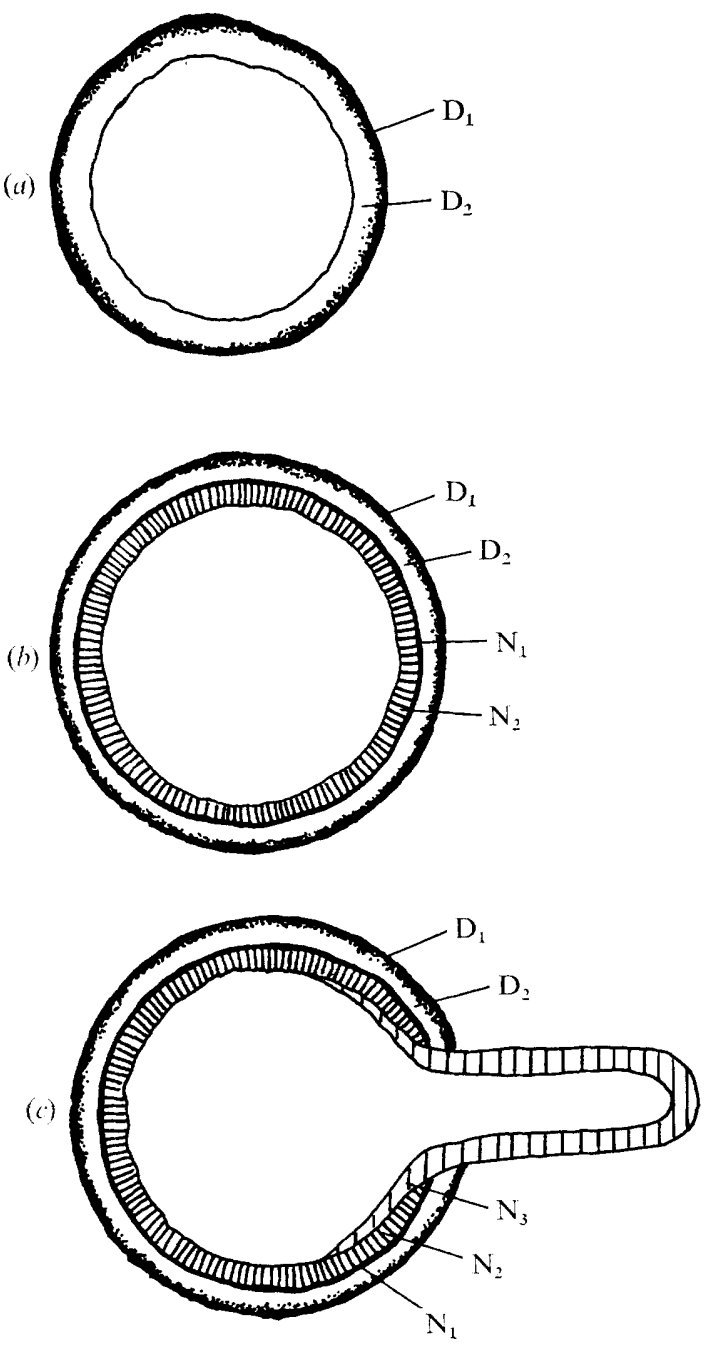

Fig. 9. Schematic representation of changes in wall structure during spore germination in Botrytis cinerea as observed with glutaraldehyde and Kellenberger fixations. (a) Dormant conidia; $(b)$ swollen conidium, 4 to $6 \mathrm{~h}$. after inoculation; $(c)$ conidium with germ tube, approximately $10 \mathrm{~h}$. after inoculation. $D_{1}$ and $D_{2}$ represent wall layers present in the dormant spore. $N_{1}, N_{2}$ and $N_{3}$ represent wall layers formed during spore germination with the $\mathrm{N}_{3}$ layer forming the germ-tube wall.

\section{DISCUSSION}

Differentiation of fungal spore walls will be apparent in transmission electron microscopy only if there are differences in the electron transparency of adjacent layers. Such differences could result directly from chemical differences, e.g. the presence of melanin in some layers but not others, or be due to differential uptake of electron dense material during fixation and staining procedures. Our results show that, at least for some spores, the Kellenberger and glutaraldehyde procedures are better spore-wall fixatives and 'stains' than $\mathrm{KMnO}_{4}$. It is possible that slight differences in the lipid content of adjacent wall layers is emphasized by treatment with osmium tetroxide. We also consider that the use of Spurr's low viscosity 
embedding medium gave better infiltration of Botrytis cinerea spores, especially dormant spores, than did other embedding media.

In germinating spores the $\mathrm{N}_{1}$ layer is designated a wall layer because it was consistently observed between the $\mathrm{N}_{2}$ and $\mathrm{D}_{2}$ layers. It may, however, merely represent the junction between the $\mathrm{N}_{2}$ and $\mathrm{D}_{2}$ layers. It never showed any invagination into either of these layers. Wall morphology and the measurements of wall thicknesses not only demonstrated the deposition of new wall material during germination but also suggested that the spore wall grew by apposition rather than intussusception.

Bartnicki-Garcia et al. (1968 b) considered that the apical corpuscle of Mucor rouxii might be derived from a Woronin body. We do not consider this to be true of the apical corpuscle of Botrytis cinerea since, unlike Woronin bodies, it was observed before septum formation. Furthermore, the apical corpuscle had an electron-dense and slightly membranous core whilst the Woronin bodies showed no substructure. The apical corpuscle has not been observed in the dormant spore and may therefore be involved in events related to germ-tube emergence (e.g. dissolution of the spore wall).

The present study indicates that earlier accounts of Botrytis cinerea conidia based on $\mathrm{KMnO}_{4}$ fixed material alone (Hawker \& Hendy, I963; Buckley et al. 1966) gave a misleading impression of wall differentiation during germination. We therefore suggest that $B$. cinerea be transferred from type I to type III of Bartnicki-Garcia's classification of fungi. Future studies with Kellenberger and glutaraldehyde fixatives may show that the position of other spores previously placed in Bartnicki-Garcia's type I may also have to be reconsidered. Eventually the group itself may have to be abandoned. As a result, the theory that the way in which a spore germinates may reflect its evolutionary history and hence be of taxonomic significance (Hawker et al. 1970) may have to be reconsidered.

The authors wish to thank the Medical Research Council for their support of this work.

\section{REFERENCES}

BARnes, M. \& PARKer, M. S. (I966). The increase in size of mould spores during germination. Transactions of the British Mycological Society 49, 487-494.

Bartnicki-Garcia, S. (1968). Cell wall chemistry, morphogenesis and taxonomy of fungi. Annual Review of Microbiology 22, 87-108.

Bartnicki-Garcia, S., Nelson, N. \& Cota-Robles, E. (1968a). Electron microscopy of spore germination and cell wall formation in Mucor rouxii. Archiv für Mikrobiologie 63, 242-255.

Bartnicki-Garcia, S., Nelson, N. \& Cota-Robles, E. (I968 b). A novel apical corpuscle in hyphae of Mucor rouxii. Journal of Bacteriology 95, 2399-2402.

Border, D. J. \& TrincI, A. P. J. (I970). Fine structure of the germination of Aspergillus nidulans conidia. Transactions of the British Mycological Society 54, I43-I 46.

BRACKER, C. E. (1966). Ultrastructural aspects of sporangiospore formation in Gilbertella persicaria. In The Fungus Spore, pp. 39-59. Edited by M. F. Madelin. London: Butterworths.

Bracker, C. E. \& Butler, E. E. (1963). The ultrastructure and development of septa in hyphae of Rhizotonia solani. Mycologia 55, 35-58.

Brenner, O. M. \& Carroll, G. C. (1968). Fine structural correlates of growth in hyphae of Ascodesmis sphaerospora. Journal of Bacteriology 95, 658-671.

Buckley, P. M., Sjaholm, V. E. \& Sommer, N. F. (1966). Electron microscopy of Botrytis cinerea conidia. Journal of Bacteriology 91, 2037-2044.

De Duve, C. \& Wattiaux, R. (I966). Functions of lysosomes. Annual Review of Physiology 28, 435-492.

HAwker, L. E. (1966). Germination, morphological and anatomical changes. In The Fungus Spore, pp. 15I16I. Edited by M. F. Madelin. London: Butterworths.

Hawker, L. E. \& Aвbott, P. McV. (1963). An electron microscope study of maturation and germination of sporangiospores of two species of Rhizopus. Journal of General Microbiology 32, 295-298. 
HAWKER, L. E. \& HeNDY, R. J. (1963). An electron microscope study of germination of conidia of Botrytis cinerea. Journal of General Microbiology 33, 43-46.

Hawker, L. E., Thomas, B. \& Beckett, A. (I970). An electron microscope study of structure and germination of conidia of Cunninghamella elegans Lendner. Journal of General Microbiology 60, I 8 I-I89.

Kellenberger, E., RYTER, A. \& Sechaud, J. (1958). Electron microscope study of DNA-containing plasms. Journal of Biophysical and Biochemical Cytology 4, 671-676.

REYNolds, E. S. (1963). The use of lead citrate at high $\mathrm{pH}$ as an electron opaque stain in electron microscopy. Journal of Biophysical and Biochemical Cytology 17, 208-2 I 2.

Righelato, R. C., Trinci, A. P. J., Pirt, S. J. \& Peat, A. (I968). The influence of maintenance energy and growth rate on the metabolic activity, morphology and conidiation of Penicillium chrysogenum. Journal of General Microbiology 50, 399-412.

SpurR, A. R. (1969). A low-viscosity epoxy resin embedding medium for electron microscopy. Journal of Ultrastructure Research 26, $3 \mathrm{I}-43$.

TANAKA, K. (I966). Changes in ultrastructure of Aspergillus oryzae conidia during germination. Journal of General and Applied Microbiology 12, 239-246.

Trinci, A. P. J. \& GULl, K. (1970). Effect of actidione, griseofulvin and triphenyltin acetate on the kinetics of fungal growth. Journal of General Microbiology, Tokyo 6o, 287-292. 